\title{
Association Study of the Interleukin-I beta (C-5IIT) Genetic Polymorphism with Major Depressive Disorder, Associated Symptomatology, and Antidepressant Response
}

\author{
Younger W-Y Yu', Tai-Jui Chen², Chen-Jee Hong ${ }^{3,4}$, Hung-Mei Chen ${ }^{3}$ and Shih-Jen Tsai*,3,4 \\ 'Yu's Psychiatric Clinic, Kaohsiung, Taiwan, ROC; ${ }^{2}$ Kai-Suan Psychiatric Hospital, Kaohsiung, Taiwan, ROC; ${ }^{3}$ Department of Psychiatry, Veterans \\ General Hospital-Taipei, Taipei, Taiwan, ROC; ${ }^{4}$ Division of Psychiatry, School of Medicine, National Yang-Ming University, Taipei, Taiwan, ROC
}

Proinflammatory cytokines, including interleukin (IL)- I beta, are suggested to have a role in the pathogenesis of major depressive disorder (MDD) and be related to the therapeutic effects of antidepressants. To elucidate a genetic predisposition of MDD, we studied biallelic polymorphism in the promoter region (position -5II) of the IL- Ibeta gene in I57 patients with MDD and in II 2 controls. We also examined the association of this polymorphism and fluoxetine therapeutic response in 119 MDD patients who received a 4-week fluoxetine treatment. No significant difference was found in the genetic polymorphism between MDD patients and controls. However, MDD patients who were homozygous for the -5 I I T allele of the IL-I beta gene had a trend of less severity of depressive symptoms and more favorable fluoxetine therapeutic response than - 5 I I C carriers. Further study with a larger sample is needed to clarify the role of the $\mathrm{IL}$ - I beta genetic polymorphisms in the symptoms and treatment effects in MDD.

Neuropsychopharmacology (2003) 28, I I 82-I I 85, advance online publication, 2 April 2003; doi: I0. I038/sj.npp. 1300 I72

Keywords: interleukin- I beta; major depressive disorders; polymorphism; selective serotonin reuptake inhibitors; treatment response

\section{INTRODUCTION}

Major depressive disorder (MDD) has a complex etiology with biological, psychological, and environmental components, and has been associated with impaired immune function and increased susceptibility to infectious disease. Cytokines, a heterogeneous group of pleiotropic polypeptides, are closely associated with the immune system and the inflammatory process. Cytokines also have various functions in the brain. Peripherally released cytokines can be transported from the blood into the brain by active transport systems. The activated glial cells can produce cytokines by a feedback mechanism and the cytokines can strongly influence the monoaminergic neurotransmitter systems (Muller and Ackenheil, 1998). Recently, increasing data have suggested that cytokines may be involved in the pathophysiology and the somatic consequences of MDD (for review see Licinio and Wong, 1999; Dantzer et al, 1999).

*Correspondence: Shih-Jen Tsai, Department of Psychiatry, Veterans General Hospital-Taipei, No. 201, Shih-Pai Road, Sec. 2, I1217, Taipei, Taiwan, ROC, Tel: +886 -2 28757027 ext. 276, Fax: +886 -2 2872 5643, E-mail: sjtsai@vghtpe.gov.tw

Received 10 May 2002; revised 07 January 2003; accepted 13 January 2003

Online publication: 20 January 2003 at http://www.acnp.org/citations/ Npp0 I 2003462/default.pdf
Among the cytokines, animal studies and clinical studies have demonstrated that interleukin (IL)-1beta, a major proinflammatory cytokine, may have a special role in the pathogenesis and somatic consequences of MDD, as well as in the effects of antidepressant treatment. Exogenous administration of IL-1beta to rats has been found to produce some depressive-like symptoms including anorexia, disturbed sleep pattern, and anhedonia (Connor and Leonard, 1998), which are also found in humans treated with cytokine immunotherapy (Capuron et al, 2000). Connor and Leonard (1998) also found that these behavioral changes were concurrently associated with an activation of hypothalamic pituitary adrenal axis activity, a phenomenon commonly found in MDD patients. These behavioral changes induced by IL-1beta could be attenuated by antidepressant treatment (Castanon et al, 2001). Additionally, intracerebroventricular administration of an IL-1 receptor antagonist (Maier and Watkins, 1995) can block the development of the behavioral deficits in a learned helpless model of depression.

IL-1beta levels have been examined under several experimental conditions in MDD patients. Some of the results showed an increase in the blood or cerebrospinal levels of this cytokine in depressed patients (Levine et al, 1999; Anisman et al, 1999; Owen et al, 2001). Furthermore, cerebrospinal IL-1beta levels were correlated with the severity of depression (Levine et al, 1999), age of onset 
(Anisman et al, 1999), and duration of illness (Anisman et al, 1999). However, several studies have found that the ILlbeta levels were unchanged in MDD patients (Rothermundt et al, 2001; Kagaya et al, 2001; Brambilla and Maggioni, 1998) and were not correlated with the severity of depression (Rothermundt et al, 2001). Furthermore, Weizman et al (1994) found a significant reduction in IL-1beta production in untreated MDD patients compared to normal controls and a significant increase of IL-1beta synthesis after drug treatment.

Considering the close relation between IL-1beta and MDD, the IL-1beta gene may therefore be considered a candidate gene for the investigation of MDD. In 1992, Pociot et al identified a biallelic (C/T) polymorphism in the promoter region (position -511) of the IL-1beta gene (Locus: 2q14) and demonstrated that $-511 \mathrm{~T}$ homozygous individuals secreted significantly more IL-1beta than heterozygous individuals, who secreted significantly more than -511C homozygous individuals. In this study, we investigated the possible association of this polymorphism with MDD and its clinical symptoms as well as therapeutic response.

\section{METHODS}

The study was an add-on to another research project (Yu et $a l, 2002$ ) and was approved by the Institution Review Board in Veteran General Hospital-Taipei. A total of 157 psychiatric outpatients (age range 18-79 years) who met the Diagnostic and Statistical Manual of the American Psychiatric Association (DSM-IV) criteria for MDD were studied. The diagnoses were based on clinical interview. Other inclusion criteria were: (1) a minimum baseline score of 18 on the 21-item Hamilton Depression Rating Scale (HAM-D) (Hamilton, 1967) and (2) presence of depressive symptoms for at least 2 weeks before entry into the study, without antidepressant treatment (patients were fresh cases or had quit antidepressant for more than 2 weeks). Exclusion criteria were additional diagnoses on Axis I (including substance abuse, generalized anxiety disorders, panic disorders, or obsessive compulsive disorders) of the DSM-IV, personality disorders, pregnancy, attempted suicide, and major medical and/or neurological disorders. In all, 112 normal controls, who were recruited mostly from the medical staff and were interviewed to rule out psychotic or mood disorders, were included for association study. The assessment of MDD patients and controls was done by a senior psychiatrist (YWY). The sample consisted entirely of ethnic Han Chinese, with informed consents obtained from all participants.

Of the 157 MDD patients, 119 (male: 70; female: 49; mean age 44.6 (16.4) years) took fluoxetine (range: $20-60 \mathrm{mg} /$ day; mean 30.6 (10.4) g/day) and received treatment efficacy evaluation with the HAM-D before and after the 4-week fluoxetine treatment by one investigator (YWY), who was blinded to the patient's genotype. Therapeutic response was evaluated by the percentage score reduction in total HAM-D scores ((baseline score-4-week score) $\times 100 /$ baseline score). 'Responders' were defined as having a minimum of $50 \%$ reduction of the initial HAM-D total score after 4 weeks of fluoxetine treatment and 'remitters' were defined as subjects having a HAM-D total score of 7 or less points after 4 weeks of mediation.

Genotyping of the C-511T polymorphism of the IL-1beta gene was performed using a polymerase chain reaction (PCR)-restriction fragment length polymorphism (RFLP)based method described by Mansfield et al (1994). Briefly, a 304-bp PCR fragment of the IL-1beta promoter region was amplified using the following primers: 5'-TGGCATTGATCTGGTTCATC- $3^{\prime}$ and 5'-GTTTAGGAATCTTCCCACTT- $3^{\prime}$. The products were digested with AvaI on a $2 \%$ ethidium bromide-stained agarose gel. This gave products that either remained intact $(-511 \mathrm{~T}$ allele) or were cut into two fragments of 190 and $114 \mathrm{bp}(-511 \mathrm{C}$ allele). The potential problems of partial digestion and PCR contamination were monitored using a control sample with $\mathrm{C} / \mathrm{C}$ genotype and a blank, respectively, in each batch of the experiment.

The categorical data were analyzed using the $\chi^{2}$-test or Fisher's exact test as appropriate. Differences in continuous variables were evaluated by Student's $t$-test or one-way analysis of variance followed by the LSD multiple range tests for comparison among groups. Data are presented as mean $\pm \mathrm{SD}$.

\section{RESULTS}

The age (MDD: $44.5 \pm 16.3$ years; controls: $42.1 \pm 12.2$ years) and sex (male/female: MDD: 67/90; controls: 45/67) distributions of the MDD patients and the control population were similar $\left(t=1.35, \mathrm{df}=267, p=0.177\right.$ and $\chi^{2}=0.17$, $\mathrm{df}=1, p=0.708$, respectively). The genotypes and allele distribution for the IL-1beta-gene C-511T polymorphism for the MDD group and controls are shown in Table 1. The distributions of the genotype for MDD cases and controls were in Hardy-Weinberg equilibrium. There is no sex difference in -511 allele frequency in MDD patients $\left(\chi^{2}=0.33, \quad \mathrm{df}=1, \quad p=0.643\right)$ or control population $\left(\chi^{2}=0.01, \mathrm{df}=1, p=1.000\right)$. Comparison of the two groups showed no significant difference in either genotype $\left(\chi^{2}=2.86, \quad \mathrm{df}=2, \quad p=0.240\right) \quad$ or allelic frequencies $\left(\chi^{2}=2.46, \mathrm{df}=1, p=0.134\right)$.

Since administration of IL-1beta to rats has been found to produce some depressive-like symptoms including anorexia and disturbed sleep pattern (Connor and Leonard, 1998), we compared the baseline total and specific HAM-D scores (insomnia and somatic GI symptoms) among three genotypic groups in $119 \mathrm{MDD}$ patients (Table 2). The baseline total HAM-D score and score on the 'early insomnia' item were different among the three genotypic groups $(p=0.012$ and 0.029 , without correction for multiple comparisons). Further analysis demonstrated that patients homozygous for $-511 \mathrm{~T}$ had lower scores than patients who were $-511 \mathrm{C}$ allele carriers in baseline total HAM-D score and score on the 'early insomnia' item. The HAM-D score change after 4 weeks of fluoxetine treatment was not significantly different among the patients in the three genotypic groups; however, a trend between the percentage of patients with a response to treatment, as measured by improved HAM-D score, and the number of $-511 \mathrm{~T}$ allele was found $(-511 \mathrm{C} / \mathrm{C}$ : $18.9 \% ;-511 \mathrm{C} / \mathrm{T}$ : $37.7 \%$; $-511 \mathrm{~T} / \mathrm{T}$ : $46.2 \% ; p=0.081$ ) (Table 2). Only four patients were 
Table I Interleukin- I beta Genotype and Allele Distributions in 157 Major Depressive Patients and I 12 Normal Control Subjects

\begin{tabular}{|c|c|c|c|c|c|c|c|c|}
\hline \multirow[b]{2}{*}{ Group } & \multirow[b]{2}{*}{$n$} & \multicolumn{3}{|c|}{ Genotypes } & \multirow[b]{2}{*}{$p$} & \multicolumn{2}{|c|}{ Allele frequency } & \multirow[b]{2}{*}{$p$} \\
\hline & & $\mathrm{C} / \mathrm{C}$ & $\mathrm{C} / \mathrm{T}$ & $\mathbf{T} / \mathbf{T}$ & & C & $\mathbf{T}$ & \\
\hline $\begin{array}{l}\text { Patients } \\
\text { Controls }\end{array}$ & $\begin{array}{l}157 \\
112\end{array}$ & $\begin{array}{l}50(31.8) \\
26(23.2)\end{array}$ & $\begin{array}{l}84(53.5) \\
64(57.1)\end{array}$ & $\begin{array}{l}23(14.6) \\
22(19.6)\end{array}$ & 0.240 & $\begin{array}{l}58.6 \\
51.8\end{array}$ & $\begin{array}{l}41.4 \\
48.2\end{array}$ & 0.134 \\
\hline
\end{tabular}

Table 2 Baseline Total and Specific HAM-D Scores, and Fluoxetine Therapeutic Response Among the Three Interleukin-I beta Genotypic Groups in 119 Major Depressive Patients

\begin{tabular}{|c|c|c|c|c|c|}
\hline & \multicolumn{3}{|c|}{ Interleukin-I beta Genotypes } & \multirow[b]{2}{*}{$\chi^{2}$ or F; df } & \multirow[b]{2}{*}{$\mathbf{p}$} \\
\hline & $\begin{array}{c}\text { C/C } \\
(n=37)\end{array}$ & $\begin{array}{c}C / T \\
(n=69)\end{array}$ & $\begin{array}{c}\mathbf{T} / \mathbf{T} \\
(n=13)\end{array}$ & & \\
\hline \multicolumn{6}{|l|}{ Baseline HAM-D scores } \\
\hline Insomnia, early & $1.8(0.4)$ & $1.7(0.6)$ & $1.4(0.7)$ & $3.67 ; 118$ & 0.029 \\
\hline Insomnia, middle & $1.7(0.5)$ & $1.8(0.5)$ & $1.5(0.5)$ & $1.75 ; 118$ & 0.178 \\
\hline Insomnia, late & $1.7(0.6)$ & $1.8(0.4)$ & $1.5(0.5)$ & $1.95 ; 118$ & 0.147 \\
\hline Somatic Gl symptoms & $2.2(0.7)$ & $1.9(0.7)$ & $1.9(0.4)$ & I.I।; 118 & 0.147 \\
\hline HAMD total & $32.1(5.0)$ & $30.7(4.1)$ & $27.6(5.1)$ & $4.62 ; 118$ & 0.012 \\
\hline Total HAM-D score change (\%) & $31.0(23.0)$ & $39.2(22.2)$ & $32.4(22.7)$ & $2.20 ; 118$ & 0.225 \\
\hline Responders/nonresponders & $7 / 30$ & $26 / 43$ & $6 / 7$ & $5.03 ; 2$ & 0.081 \\
\hline Remitters/nonremitters & 0/37 & $2 / 67$ & $2 / 11$ & $7.12 ; 2$ & 0.028 \\
\hline
\end{tabular}

Data are mean (SD).

HAM-D score change $(\%)=($ baseline score-4-week score $) \times 100 /$ baseline score.

'remitters' and the percentage of the 'remitters' was not significantly different among the three genotype groups (Table 2). No significant correlation was found between HAM-D score change and patient's age or fluoxetine dosage.

\section{DISCUSSION}

In this study, MDD patients who were homozygous for the IL-1beta gene -511T had a trend of lower baseline 'early insomnia' and total HAMD-scores (less severity), and of favorable response to fluoxetine treatment than patients of the other two genotypic groups. There are several implications of these findings. First, a previous study showed that $511 \mathrm{~T}$ homozygous individuals secreted more IL-1beta than heterozygous individuals, who secreted significantly more than -511C homozygous individuals (Pociot et al, 1992). If this phenomenon is also present in our population, it indicates that patients with more IL-1beta production had less severe depressive symptoms. This is in contrast with the finding that IL-1beta levels were positively correlated with the severity of depression (Levine et al, 1999) and that IL1beta administration could disturb sleep (Connor and Leonard, 1998). Since our study is a preliminary study and no correction was made in the obtained $p$-values for multiple testing. If we take multiple testing into account (eight tests, Table 2), the threshold of $5 \%$ significance should be about 0.063 . After correction for multiple testing, the study is negative and there are no statistical results. Future studies with larger samples, including baseline plasma or CSF IL1-1beta levels, are needed to test these hypotheses. Second, our results may indicate that only a linkage disequilibrium between the $-511 \mathrm{~T}$ allele and a different mutation in the IL-1beta gene, or another nearby gene exists in MDD patients. Third, the association of the IL-1beta genetic polymorphism and depressive symptoms may be more prominent in some subtypes of MDD patients. Nelson et al (1999) compared depressive behaviors in adult and aged mice after central injection of IL-1beta and found that centrally administered IL-1beta depressed food intake more in aged mice than in adult mice. This finding suggests that the association between IL-1beta and depressive symptoms may be more prominent in geriatric MDD patients. Finally, homozygous for the IL-1beta gene -511T had a trend of favorable response to fluoxetine treatment than patients of the other two genotypic groups. Future studies using larger samples are needed to resolve fully the question of the possible involvement of IL-1beta genetic polymorphism in therapeutic response.

This study found no association between MDD and the studied IL-1beta genetic polymorphism. Our negative findings suggest that the IL-1beta gene C-511T polymorphism is not to be involved in MDD susceptibility. It is also possible that additional variants of the gene, not detected by analysis of this C-511T polymorphism, may influence the development of MDD. Another possible explanation for the lack of association demonstrated for this IL-1beta gene polymorphism and MDD is the phenotypic heterogeneity characteristic of MDD (Winokur, 1997). If the IL-1beta gene is an uncommon disease locus for MDD or one of the relatively modest effects, our power to detect the gene would be reduced. Since depression is commonly found in autoimmune diseases (Utset et al, 1994; Elsehety and Bertorini, 1997) or in patients who receive cytokine immunotherapy (Capuron et al, 2000), it would be of interest to determine whether genetic polymorphisms of 
cytokines may be associated with the development of depression in these patients.

One limitation of the present study is that the duration for fluoxetine evaluation is 4 weeks, which is the minimal time expected for a treatment response and we may only identify rapid responders, not all responders, to fluoxetine treatment. Further study with longer observation period is needed to identify all responders. Another limitation is that the diagnosis of MDD was based on a clinical interview instead of a structured diagnostic interview. Further, the control group is only screened for psychotic or mood disorders in our study, without assessment for family history or other psychiatric problems that are often comorbid with MDD, which may decrease the power to find difference between the control and MDD groups.

To our knowledge, this is the first genetic study of genetic polymorphism of cytokines in MDD. Our preliminary results suggest that the IL-1beta gene $\mathrm{C}-511 \mathrm{~T}$ polymorphism may be related to the severity of MDD and to early insomnia in MDD patients. It is also possible that the IL-1beta genetic polymorphism plays a role in the antidepressant therapeutic response. Furthermore, previous studies have found that other cytokines are related to depressive symptoms or therapeutic effect. For example, a recent report found that pretreatment mononuclear cell IL-6 level was significantly lower in patients who were antidepressant responders compared with those who were antidepressant nonresponders (Lanquillon et al, 2000). Maes et al (1993, 1995) demonstrated that plasma concentrations of IL-6 were significantly higher in MDD subjects than in healthy controls and IL- 6 activities were positively correlated with postdexamethasone cortisol values. These findings suggested that other cytokines, such as IL-6, could be of candidate genes for future studies in MDD.

\section{ACKNOWLEDGMENTS}

This work was supported by grant NSC 90-2314-B-075-068 from the National Science Council, Taiwan, ROC, and grant VGH89-328 from Veterans General Hospital-Taipei.

\section{REFERENCES}

Anisman H, Ravindran AV, Griffiths J, Merali Z (1999). Endocrine and cytokine correlates of major depression and dysthymia with typical or atypical features. Mol Psychiatry 4: 182-188.

Brambilla F, Maggioni M (1998). Blood levels of cytokines in elderly patients with major depressive disorder. Acta Psychiatr 97: 309-313.

Capuron L, Ravaud A, Dantzer R (2000). Early depressive symptoms in cancer patients receiving interleukin 2 and/or interferon alfa-2b therapy. J Clin Oncol 18: 2143-2151.

Castanon N, Bluthe RM, Dantzer R (2001). Chronic treatment with the atypical antidepressant tianeptine attenuates sickness behavior induced by peripheral but not central lipopolysaccharide and interleukin-1beta in the rat. Psychopharmacologia 154: $50-60$.

Connor TJ, Leonard BE (1998). Depression, stress and immunological activation: the role of cytokines in depressive disorders. Life Sci 62: 583-606.

Dantzer R, Wollman E, Vitkovic L, Yirmiya R (1999). Cytokines and depression: fortuitous or causative association? $\mathrm{Mol}$ Psychiatry 4: 328-332.
Elsehety A, Bertorini TE (1997). Neurologic and neuropsychiatric complications of Crohn's disease. South Med J 90: 606-610.

Hamilton M (1967). Development of a rating scale for primary depressive illness. Br J Soc Clin Psychol 6: 278-296.

Kagaya A, Kugaya A, Takebayashi M, Fukue-Saeki M, Saeki T, Yamawaki S (2001). Plasma concentrations of interleukin-1beta, interleukin-6, soluble interleukin-2 receptor and tumor necrosis factor alpha of depressed patients in Japan. Neuropsychobiology 43: $59-62$

Lanquillon S, Krieg JC, Bening-Abu-Shach U, Vedder H (2000). Cytokine production and treatment response in major depressive disorder. Neuropsychopharmacology 22: 370-379.

Levine J, Barak Y, Chengappa KN, Rapoport A, Rebey M, Barak V (1999). Cerebrospinal cytokine levels in patients with acute depression. Neuropsychobiology 40: 171-176.

Licinio J, Wong ML (1999). The role of inflammatory mediators in the biology of major depression: central nervous system cytokines modulate the biological substrate of depressive symptoms, regulate stress-responsive systems, and contribute to neurotoxicity and neuroprotection. Mol Psychiatry 4: 317-327.

Maes M, Meltzer HY, Bosmans E, Bergmans R, Vandoolaeghe E, Ranjan R (1995). Increased plasma concentrations of interleukin-6, soluble interleukin-6, soluble interleukin-2 and transferrin receptor in major depression. J Affect Disord 34: 301-309.

Maes M, Scharpe S, Meltzer HY, Bosmans E, Suy E, Calabrese J (1993). Relationships between interleukin-6 activity, acute phase proteins, and function of the hypothalamic-pituitary-adrenal axis in severe depression. Psychiatry Res 49: 11-27.

Maier SF, Watkins LR (1995). Intracerebroventricular interleukin1 receptor antagonist blocks the enhancement of fear conditioning and interference with escape produced by inescapable shock. Brain Res 695: 279-282.

Mansfield JC, Holden H, Tarlow JK, Di Giovine FS, McDowell TL, Wilson AG (1994). Novel genetic association between ulcerative colitis and the anti-inflammatory cytokine interleukin-1 receptor antagonist. Gastroenterology 106: 637-642.

Muller N, Ackenheil M (1998). Psychoneuroimmunology and the cytokine action in the CNS: implications for psychiatric disorders. Prog Neuropsychopharmacol Biol Psychiatry 22: 1-33.

Nelson KP, Marks NL, Heyen JR, Johnson RW (1999). Behavior of adult and aged mice before and after central injection of interleukin-1beta. Physiol Behav 66: 673-679.

Owen BM, Eccleston D, Ferrier IN, Young AH (2001). Raised levels of plasma interleukin-1beta in major and postviral depression. Acta Psychiatr Scand 103: 226-228.

Pociot F, Molvig J, Wogensen L, Worsaae H, Nerup J (1992). A TaqI polymorphism in the human interleukin-1 beta (IL-1 beta) gene correlates with IL-1 beta secretion in vitro. Eur J Clin Invest 22: 396-402.

Rothermundt M, Arolt V, Peters M, Gutbrodt H, Fenker J, Kersting A (2001). Inflammatory markers in major depression and melancholia. J Affect Disord 63: 93-102.

Utset TO, Golden M, Siberry G, Kiri N, Crum RM, Petri M (1994). Depressive symptoms in patients with systemic lupus erythematosus: association with central nervous system lupus and Sjogren's syndrome. J Rheumatol 21: 2039-2045.

Weizman R, Laor N, Podliszewski E, Notti I, Djaldetti M, Bessler H (1994). Cytokine production in major depressed patients before and after clomipramine treatment. Biol Psychiatry 35: 42-47.

Winokur G (1997). All roads lead to depression: clinically homogeneous, etiologically heterogeneous. J Affect Disord 45: 97-108.

Yu YWY, Tsai SJ, Chen TJ, Lin CH, Hong CJ (2002). Association study of the serotonin transporter promoter polymorphism and symptomatology and antidepressant response in major depressive disorders. Mol Psychiatry 7: 1115-1119. 